This item was submitted to Loughborough's Research Repository by the author.

Items in Figshare are protected by copyright, with all rights reserved, unless otherwise indicated.

\title{
Interaction of sub-microsecond pulsed electric field with bacterial cells
}

PLEASE CITE THE PUBLISHED VERSION

PUBLISHER

(C) IEEE

VERSION

VoR (Version of Record)

LICENCE

CC BY-NC-ND 4.0

\section{REPOSITORY RECORD}

Chalise, Priya R., Stefano Perni, Gilbert Shama, Bucur M. Novac, Ivor R. Smith, and Michael G. Kong. 2019. "Interaction of Sub-microsecond Pulsed Electric Field with Bacterial Cells". figshare.

https://hdl.handle.net/2134/5234. 
This item was submitted to Loughborough's Institutional Repository (https://dspace.lboro.ac.uk/) by the author and is made available under the following Creative Commons Licence conditions.

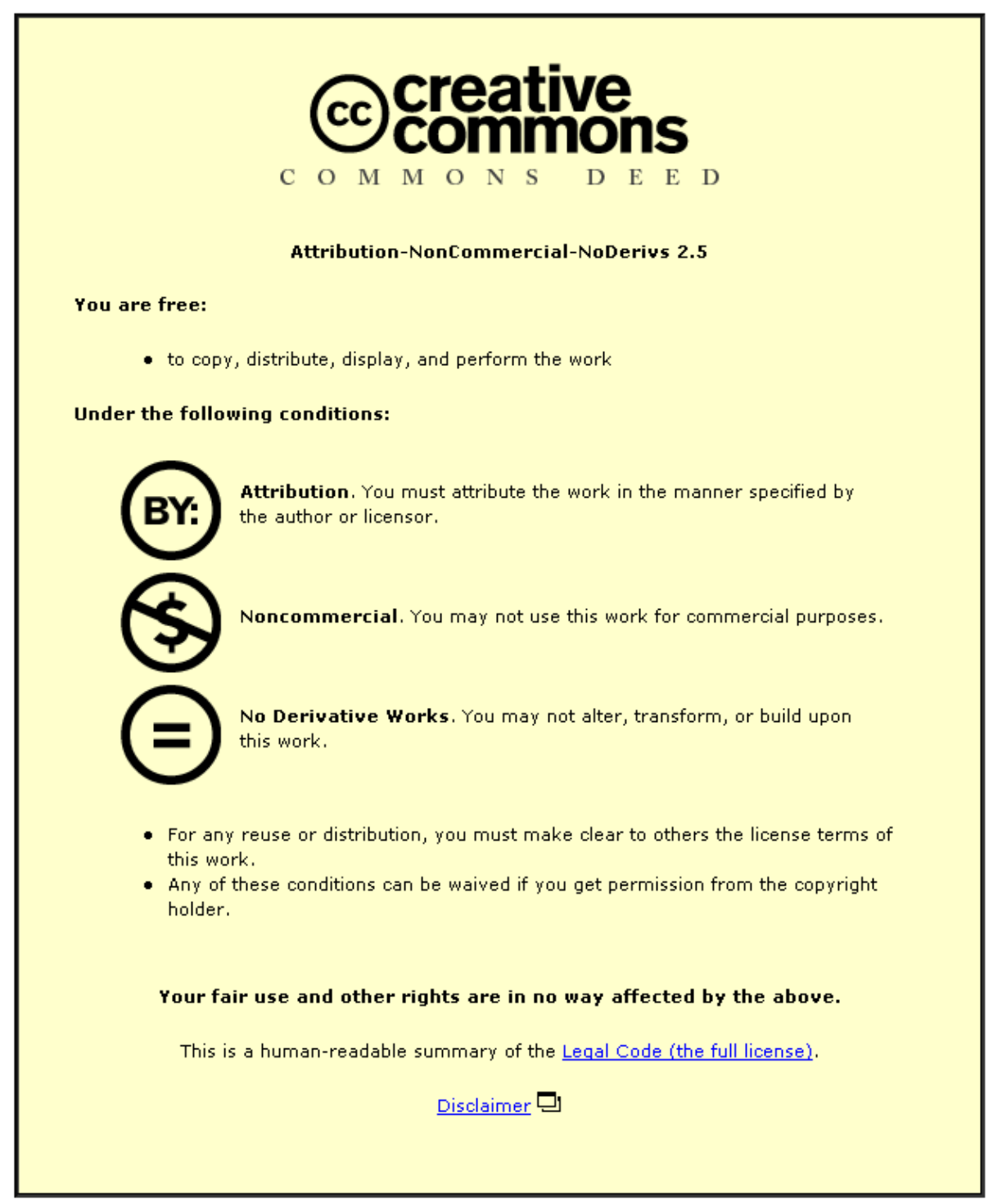

For the full text of this licence, please go to: http://creativecommons.org/licenses/by-nc-nd/2.5/ 


\title{
Interaction of Sub-Microsecond Pulsed Electric Field With Bacterial Cells
}

\author{
Priya R Chalise ${ }^{1}$, Stefano Perni ${ }^{2}$, Gilbert Shama ${ }^{2}$, Bucur M Novac ${ }^{1}$, Ivor R Smith ${ }^{1}$ and \\ Michael G Kong ${ }^{1}$ \\ ${ }^{1}$ Department of Electronics and Electrical Engineering, Loughborough University, Loughborough, Leicestershire \\ LE11 3TU, UK \\ ${ }^{2}$ Department of Chemical Engineering, Loughborough University, Loughborough, Leicestershire LE11 3TU, UK
}

\begin{abstract}
In the bacterial decontamination of liquid foods, the use of a sub microsecond pulsed electric field is of significant interest because it offers advantages such as negligible thermal effects, superior energy efficiency, and a much-reduced probability of medium breakdown. The reduced pulse duration also effects the mechanism by which sub microsecond pulses inactivate bacterial cells. We provide insight into possible bacterial inactivation mechanisms by sub-microsecond electric pulse with the aid of a common bacterium-wild type Escherichia coli and its mutants. Two pulsed power sources have been designed, developed and tested-one with a pulse duration of $32 \mathrm{ns,}$ the other $700 \mathrm{~ns}$, and both are capable of establishing sufficiently high electric field intensity. The experimental results suggest that bacterial inactivation by $700 \mathrm{~ns}$ pulses is due to electrical breakdown of the outer cell membrane, whereas inactivation by $32 \mathrm{~ns}$ pulses is possibly due to interaction with intracellular structures.
\end{abstract}

\section{INTRODUCTION}

Pulsed electric field (PEF) technique has been used for bacterial decontamination of liquid foods through commercially available devices operating with- pulse durations of several microsecond ( $\mu \mathrm{s})[1,2,3]$. The major drawbacks associated with multi- $\mu$ s pulses are low decontamination efficiency and early electrical breakdown. These drawbacks may be overcome by the use of high-intensity and sub- $\mu$ S PEF sources built with advanced pulsed power concepts. The reduced pulse duration may also influence the mechanism by which PEF inactivates bacterial cells. If the external pulse duration is much less than the charging time constant of cell membrane $(<100 \mathrm{~ns})$, it is possible that the electric field could penetrate the cell membrane and interact with intracellular components or organelles. This effect may be utilized not only for efficient bacterial-decontamination, but also for other subcellular effects such as programmed cell death of bacteria cell, inactivation of viruses inside cells, or many other unexplored biomedical applications. Some previous investigations on the use of sub- $\mu$ s pulses to inactivate bacterial cells have been reported but these studies do not address the mechanism associated with bacterial inactivation $[4,5]$. The sub- $\mu$ S PEF devices have also been used with mammalian cells to study intracellular effects such as programmed cell death (apoptosis) of cancer cells [6,7]. Since the dimension and biophysical properties of bacterial cells are significantly different from mammalian cells, there is a need to address these effects in bacterial cells.

In this paper, we present a study of possible inactivation mechanisms by sub- $\mu$ S PEF treatment with the help of target cells, wild type Escherichia coli (E. coli), and some of its mutants. Two pulsed power sources have been designed, developed and tested- one with a pulse duration of $32 \mathrm{~ns}$, the other $700 \mathrm{~ns}$, and both are capable of establishing sufficiently high electric field intensity. The selection of externally applied pulse duration is based on the theoretical calculation of a charging time constant of the E. coli cell membrane.

\section{INACTIVATION MECHANISM}

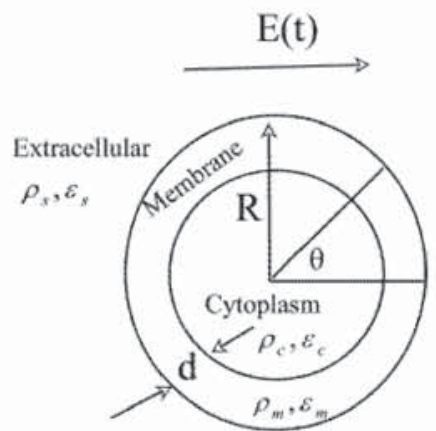

Fig. 1. Single shell model of a bacteria cell.

Bacterial inactivation mechanisms are explained using a simple single shell model as shown in Fig. 1. In this model, the cell is assumed to constitute a spherical conductive body (cytoplasm) surrounded by thin bilayer of insulating body (low conductivity cell membrane), and placed in extra cellular conducting medium. The electrical equivalent of the cell membrane is a membrane capacitance in parallel with a membrane resistance. If the externally applied pulse duration is much longer (i.e. at low frequency) than the charging time constant of the cell membrane, the resistance of the cell membrane insulates the cytoplasm from the external electric field. As a result, free 
charges build up on both the membrane surfaces. If the pulse duration and field intensity are sufficiently large, electrocompression of the membrane occurs, which leads to the formation of pores and finally cell lyses due to irreversible breakdown of the cell membrane. This is a dominating mechanism in most of the PEF bacterial decontamination by multi $\mu$ s pulses. If the pulse duration is much smaller (i.e. at high frequency) than the charging time constant of the cell membrane, the short-circuiting effect of the membrane capacitance allows the electrical field to penetrate into the cell [8]. If the electric field intensity of such pulse is sufficiently high $(100 \mathrm{kV} / \mathrm{cm})$, the resulting effect is generation of a potential difference across the intracellular organelles. The effect allows a possible interaction of electric fields with various organelles without permanent damage to the outer cell membrane.

It is important to calculate the charging time constant $\left(\tau_{m}\right)$ of the $E$. coli cell membrane because it is cell-specific. The $\tau_{m}$ of the spherical outer cell membrane using the single shell model is given by Cole [9].

$\tau_{m}=\left[\left\{\frac{1+2 V}{1-V}\right\} \frac{\rho_{s}}{2}+\rho_{C}\right] C_{m} R$

where $\mathrm{R}$ is the radius of the bacterial cell (in this case $E$. Coli), $\rho_{s}$ is the specific resistivity of extra cellular medium, $\rho_{c}$ is the specific resistivity of cytoplasm, $V$ is the volume concentration of the spheres in cell suspension, and $C_{m}$ is the specific capacitance of cell membrane. An approximate value for $C_{m}$ is given by the following equation for slab dielectric [8].

$C_{m}=\frac{\mathcal{E}_{0} \varepsilon_{r}}{d}$

Where $d(=5 \mathrm{~nm})$ is the uniform thickness of the cell membrane and $\varepsilon_{0} \varepsilon_{r}\left(=4.4 \times 10^{-11} \mathrm{AV}^{-1} \mathrm{~m}^{-1}\right)$ is permittivity of the membrane forming material [10]. With these values, $C_{m}$ is calculated as $1 \mu \mathrm{F} / \mathrm{cm}^{2}$. The value of $\mathrm{V}(=0.8)$ for face centered cubic (FCC) orientation is more realistic orientation in nonconductive cells in the suspension [11]. The values of $\mathrm{R}(=0.7$ $\mu \mathrm{m})[10]$ and $\rho_{s}(=100 \Omega . \mathrm{cm})$ [5] are widely used for $E$. Coli. However, due to a large variation in the value of $\rho_{c}(=100$ $\Omega . \mathrm{cm}$ to $500 \Omega . \mathrm{cm})[10,12,13,14]$, both the lower to upper limiting are used and $\tau_{m}$ is calculated as $52 \mathrm{~ns}$ to $81 \mathrm{~ns}$. This calculation provides a basis for selecting the pulse durations of externally applied pulse. The selected pulses satisfy the condition of $700 \mathrm{~ns}>\tau_{m}$ and $32 \mathrm{~ns}<\tau_{m}$.

\section{EXPERIMENTAL DEVICES}

The first PEF device delivering pulse of duration $32 \mathrm{~ns}$ and electrical field intensity of $100 \mathrm{kV} / \mathrm{cm}$ across the biological load was designed and fabricated at Loughborough University. The schematic diagram and output pulse shape across a biological load are illustrated in Fig. 2. The biological load includes the entire volume of cell suspension $(100 \mathrm{ml})$ which is contained in a cuvette with an inter electrode gap of $1 \mathrm{~mm}$. The repetitive pulse generator uses a Blumlein self-match configuration; metal stripe transmission line and self- breakdown pressurized spark gap switch. The transmission line is designed for characteristic impedance of $10.4 \Omega$ to match the impedance of biological load. The temporal response of the output voltage pulse measured by Tektronix high voltage probe (P6015A) and oscilloscope (Tektronix TDS 5054B), show pulse duration of $32 \mathrm{~ns}$ (FWHM) at the rise time of $8 \mathrm{~ns}$ and voltage amplitude of $10 \mathrm{kV}$.
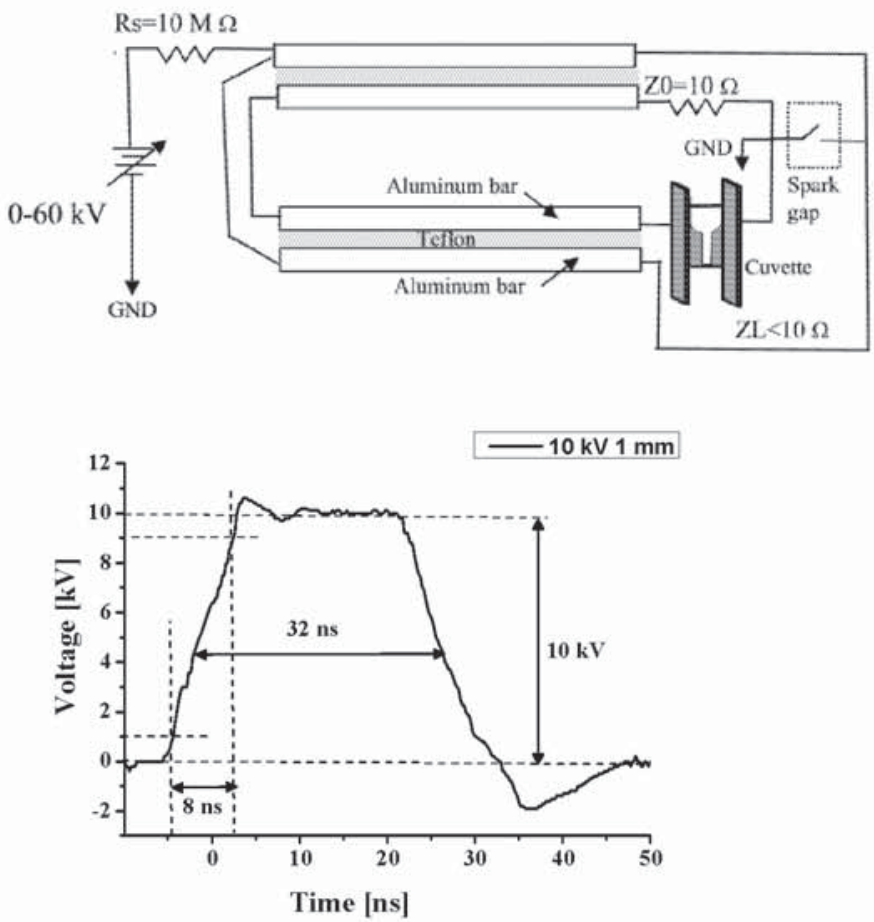

Fig. 2. Schematic diagram and output pulse across biological load of $32 \mathrm{~ns}$ pulse.

The second PEF device delivering pulse of 700 ns duration and electrical field intensity of $30 \mathrm{kV} / \mathrm{cm}$ is a high voltage trigger generator (TG-70, Maxwell Technologies Physics International, USA). The schematic diagram and output pulse shape across the biological load are illustrated in Fig. 3. The biological load in this case is the cell suspension $(400 \mathrm{ml})$ in a cuvette having a $4 \mathrm{~mm}$ inter electrode gap in order to avoid early electrical breakdown. The pulse formation is due to charging of a capacitor $(0.1 \mu \mathrm{F})$ through a series resistor and discharging to three outputs following a trigger on the spark gap switch. The temporal response of the output voltage pulse measured by North Star PVM-6 probe and oscilloscope (Tektronix TDS 5054B), show pulse duration of $700 \mathrm{~ns}$ (FWHM) at the rise time of $5 \mathrm{~ns}$ and the voltage amplitude of $12 \mathrm{kV}$. 

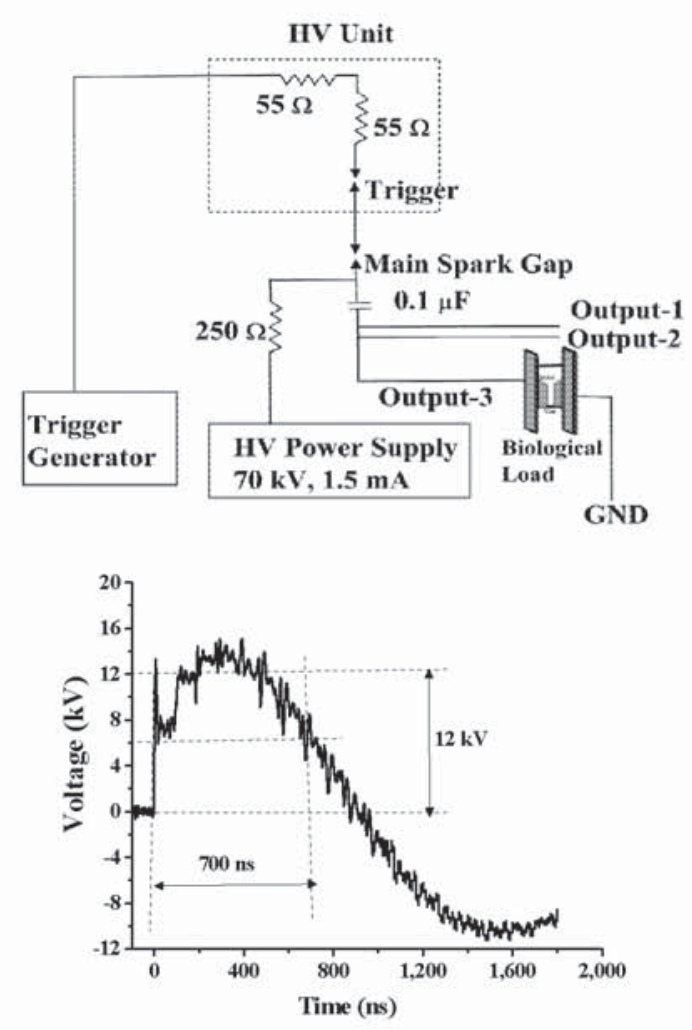

Fig. 3. Schematic diagram and output pulse across biological load of $700 \mathrm{~ns}$ pulse.

\section{BACTERIAL SAMPLE PREPARATION}

E. coli $\mathrm{K} 12$, and its mutants $\Delta \mathrm{recA}, \Delta$ soxS, and BL21 (DE3) pLysS cultures were kept on LB Agar at $4^{\circ} \mathrm{C}$; the medium was supplemented with $25 \mu \mathrm{g} / \mathrm{ml}$ chloramphenicol in all the cases when mutants were grown. Erlenmeyer flasks $(500 \mathrm{ml})$ containing $100 \mathrm{ml}$ of fresh sterile LB broth (supplemented with chloramphenicol when required) were inoculated with a loopful of bacteria. The cultures were then placed in an orbital incubator for 24 hours at $37^{\circ} \mathrm{C}$ shaken at $140 \mathrm{rpm}$. From this culture, $0.1 \mathrm{ml}$ were aseptically diluted in $100 \mathrm{ml}$ of sterile Phosphate Buffer Solution (PBS) reaching a cell concentration of approximately $10^{6} \mathrm{CFU} / \mathrm{ml}$. Aliquots $(0.1 \mathrm{ml})$ of this diluted suspension were transferred into a cuvette for PEF treatment. After treatment, $0.05 \mathrm{ml}$ were recovered from the cuvette and serially diluted in PBS. For cell enumeration the appropriate dilution was plated on LB Agar, supplemented with chloramphenicol when required, and incubated at $37^{\circ} \mathrm{C}$ for 24 hours. Each data point shown in the preceeding figures were obtained from the mean of three independent cultures. All results show the average and the standard deviation of the counts.

\section{RESULTS AND DISCUSSION}

The first set of experiments were carried out to investigate the effect of $700 \mathrm{~ns}$ and $32 \mathrm{~ns}$ pulses on the cell membrane of $E$. coli $\mathrm{K} 12$ and $E$. coli BL21(DE3) pLysS. The latter contains a plasmid bearing the gene for the enzyme lysozyme that causes the membrane to lyse if significant disturbances are produced at the membrane. If the PEF treatment affects the cell membrane, it can be expected that inactivation of BL21 (DE3) pLysS will be more rapid than in the wild type. The inactivation curves of both types of cells subjected to $700 \mathrm{~ns}$, $30 \mathrm{kV} / \mathrm{cm}$ PEF treatment are shown in Fig. 4. E. coli $\mathrm{K} 12$ is almost unaffected but $E$. coli BL21 (DE3) pLysS is rapidly decreased by $4 \log _{10}(99.99 \%)$ reduction after 15 pulses. This shows a significant difference in the inactivation kinetics of these cells and suggests that the inactivation of cells is through an external cell membrane breakdown following $700 \mathrm{~ns}$ pulse treatment.

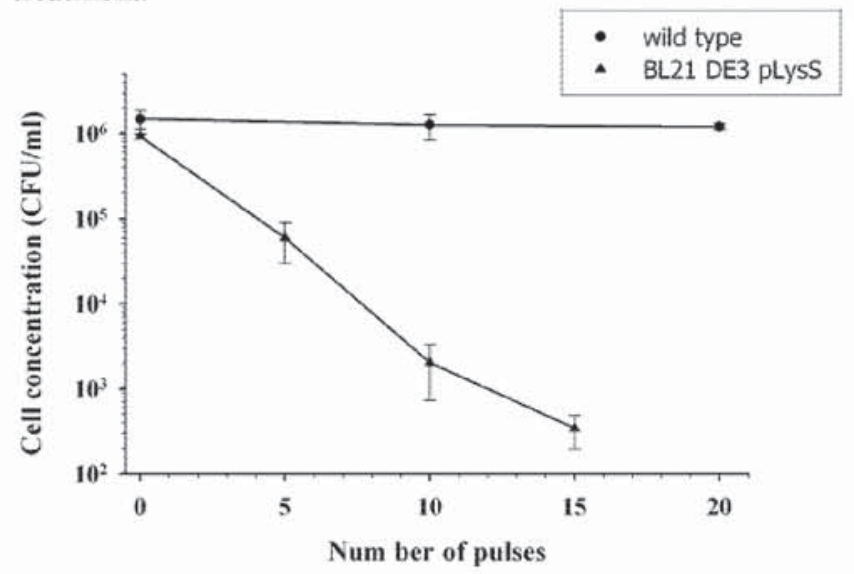

Fig. 4. Inactivation kinetics of $E$. Coli K12 and BL21(DE3) pLysS in 700 ns pulse.

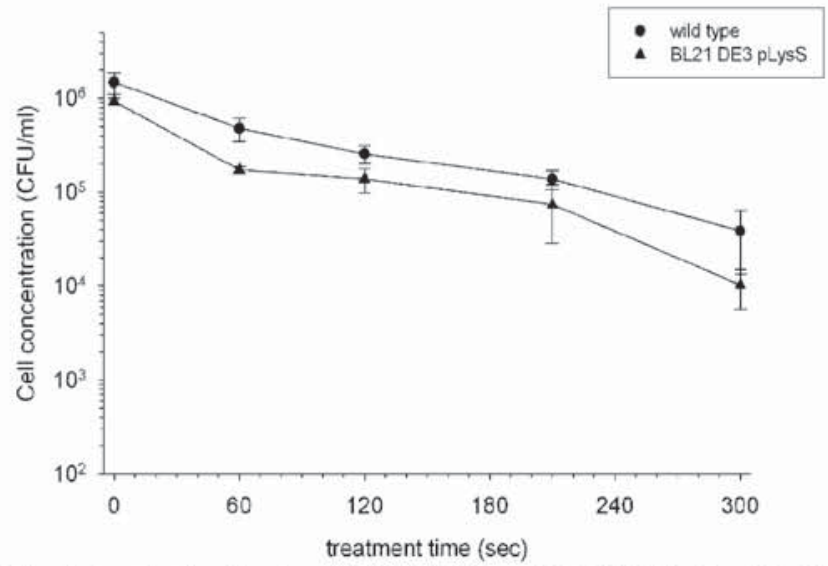

Fig. 5. Inactivation kinetics of $E$. Coli K12 and BL21(DE3) pLysS in 32 ns pulse.

The next set of experiments were carried out to investigate what other bacterial targets might be damaged by $32 \mathrm{~ns}, 100$ $\mathrm{kV} / \mathrm{cm}$ pulse. The two mutants employed here were $E$. coli $\mathrm{K} 12$ $\Delta$ recA and E. coli K12 $\Delta$ soxS. The former lacks the gene recA, which is important in the repair of damaged DNA. The inactivation curve of $\triangle \mathrm{rec} A$ may, therefore, provide information on whether DNA is damaged following $32 \mathrm{~ns}$ PEF treatment. The latter mutant lacks the recovery mechanism that is activated to deal with damage caused by oxidative species. Therefore, experiments with this mutant should reveal 
whether oxidative species are formed in the course of PEF treatment. The inactivation curves of both the mutants and the wild type E. coli $\mathrm{K} 12$ are plotted in Fig. 6. Interestingly, the inactivation kinetics of all three cells do not show any remarkable differences. This suggests that cell inactivation through DNA damage is unlikely. However, E. coli possesses more than one DNA-repair mechanism; it is, therefore, not possible to completely rule out the possibility that PEF does include DNA damage. Further studies with a greater number of mutants are therefore needed. The result for E. Coli $\Delta$ soxS is perhaps not surprising because the pulse duration, and probably also the electric field intensity, may not be sufficient to form active species in the interior of the cells.

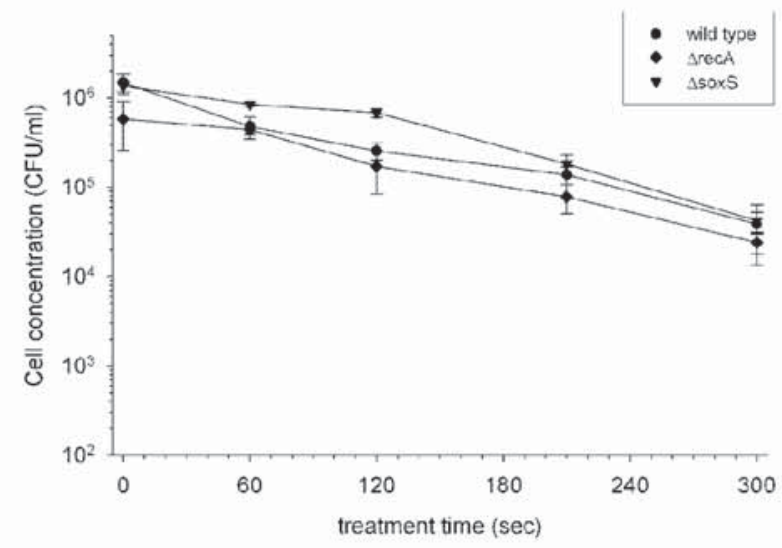

Fig. 6. Inactivation kinetics of $E$. Coli $\mathrm{K} 12, \Delta \mathrm{rec} \mathrm{A}$ and $\Delta \mathrm{SOx}$ in 32 ns pulse.

The inactivation curves of both types of cells subjected to 32 ns, $100 \mathrm{kV} / \mathrm{cm}$ at $30 \mathrm{pps}$ repetitive PEF treatment are shown in Fig. 5. Interestingly, the inactivation kinetics of both the cells are similar up to $2 \log _{10}(99 \%)$ reductions being achieved in 300 seconds. This suggests that in this case inactivation is not due to the electrical breakdown of the cell membrane with 32 ns pulses. The significance of this result is that it indicates possible electric field penetration of the cell membrane before charge build up occurs and that inactivation of cells must be occurring by some other mechanism, possibly involving the degradation of some other intracellular component(s).

We are in the process of investigating possible synergistic effects in terms of sub-lethal injury on the wild type, $E$. coli $\mathrm{K} 12$ following the treatment of the $32 \mathrm{~ns}, 100 \mathrm{kV} / \mathrm{cm}$ pulse. We have already observed a distribution of various states of injury ranging from minor recoverable, damage to complete inactivation. The treatment time in terms of repetitive pulses was found to influence significantly the occurrence and recovery of sub-lethally injured cells. The significance of sublethally injured cells is very important in food processing, as injured cells might not be detectable by normal procedures of estimating food safety. The sub-lethal injury may indicate programmed cell death of bacterial cells, but this a matter of controversy at this moment.

\section{SUMMARY}

An experimental investigation on the effect of sub- $\mu$ s pulse electric field on various mutants of- $E$. coli cells with the focus of bacterial inactivation mechanism is presented. The experimental results suggest the inactivation of the cells by the $700 \mathrm{~ns}$ pulse is due to breakdown of cell membrane, whereas the inactivation by $32 \mathrm{~ns}$ pulse is possibly due to intracellular effect. Experimental results on the effect of 32 ns pulse interaction with intracellular components such as DNA are also provided.

\section{ACKNOWLEDGMENT}

This research work is funded by Engineering and Physical Sciences Research Council (EPSRC) and Department for Environmental Food and Rural Affairs (DEFRA) of the United Kingdom.

\section{REFERENCES}

B. L. Qin et al.,"Inactivating microorganism using a pulsed electric field continuous treatment system," IEEE Trans. Industrial Appl., vol. 34 , no. 1 , pp. $43-49,1998$.

[2] P. C. Wouters "Inactivation of Microorganisms with Pulsed Electric Fields: Potential for Food Preservation," Food Biotechnology, vol. 11, pp. 193-223, 1997.

[3] S. Bendicho, A. Espachs, J Arantegui, and O martin, "Effect of high intensity pulse electric fields and heat treatments on vitamins of milk," Journal of Dairy Research, vol. 69, pp. 113-123, 2002.

[4] S. Katsuki et al., "Inactivation of Bacillus Strearothermophilus and by Pulse Electric Field," IEEE Trans. Plasma Sci., vol. 28, no.1, pp. $155-160,2000$.

[5] K. H. Schoenbach et al., "Bacterial decontamination of liquid with pulse electric fields", IEEE Trans. on Dielectrics and Electrical Insulation, vol. 7, no. 5, pp. 637-645, 2000

[6] S. J. Beebe et al.,"Nanosecond high-intensity pulsed electric fields induced apoptosis in human cells," FASEB J., vol. 17, no.1, pp. $1493,2003$.

[7] P. T. Vernier et al.,"Ultrashort pulsed electric fields induced membrane phospholipid translocation and caspace activation: differential sensitivities of Jurkat T Lymphoblasts and Rat Giloma C6 Cells," IEEE Transactions on Dielectrics and Electrical Insulation, vol. 10, no. 5, pp. 795-809, 2003.

[8] R. Pething and D. B Kell, "The Passive electrical properties of biological systems: their significance in physiology, biophysics and biotechnology", Phys. Med. Biol., vol. 32, no. 8, pp. 933-970, 1987.

[9] K. S. Cole, Trans. Faraday Soc., vol. 23, pp. 966, 1937.

[10] T. Kotnik, D. Mikalvcic and T. Slivinic, "Time course of transmembrane voltage induced by time-varying electric fields-a method for theoretical analysis and its application,"

Bioelectrochemistry and Bioenergetics, vol. 45, pp. 3-16, 1998.

[11] M. Pavlin, T. Slivinic and D. Mikalvcic, "Effective conductivity of cell suspension," IEEE Transactions on Biomedical Engineering, vol. 49 , no. 1 , pp. $77-80,2002$.

[12] K. Asami, T. Hanai, N. Koizumi, "Dielectric properties of yeast cells," J. Membr. Biol., Vol. 28, pp 169-180, 1976.

[13] C. M. Harris, D. B. Kell, "The radio-frequency dielectric properties of yeast cells measured with a rapid, automated, frequency-domain dielectric spectrometer," Bioelectrochem. Bioenerg. vol. 11, pp. $15-28,1983$.

[14] R. Holzel and I. Lamprecht, "Dielectric properties of yeast cells as determined by electrorotation,", Biochim. Biophys. Acta, vol. 11, no. 04, pp. 195-200, 1992. 